Vitaly Boiko ${ }^{1}$, Volodymyr Grishchenko ${ }^{1}$ and Mikhail Fedoseev ${ }^{2}$

\title{
SYNTHESIS AND CHARACTERIZATION OF OLIGOISOPRENE OBTAINED IN ALLYL ALCOHOL SOLUTION IN THE PRESENCE OF HYDROGEN PEROXIDE
}

\author{
IInstitute of Macromolecular Chemistry of National Academy of Sciences of Ukraine, \\ 48, Kharkivske Shose, 02160 Kyiv, Ukraine; boikovita@bigmir.net \\ 2Institute of Technical Chemistry of Ural Division of Russian Academy of Sciences, \\ PermУRussia; msfedoseev@mail.ru
}

Received: January 15, 2010 / Revised: April 24, 2010 / Accepted: J uly 23, 2010

(C) Boiko V., Grishchenko V., Fedoseev M., 2011

\begin{abstract}
The cooligomers of isoprene and allyl alcohol under the action of hydrogen peroxide have been synthesized. Using a solvent of variable composition isopropyl alcohol-allyl alcohol showed that the cooligomer yield doesn't depend on a ratio of solvent composition. Polymerization of allyl alcohol itself doesn't take place. The determination of molar weights and hydroxyl group contents in the cooligomers obtained in both alcohols showed that the cooligomer obtained in the allyl alcohol has an increased functionality 3.5 against 2 in single isopropyl alcohols.
\end{abstract}

Keywords: copolymerization, isoprene, allyl alcohol, hydrogen peroxide, hydroxyl groups, functionality.

\section{Introduction}

Elastomers based on liquid rubbers with hydroxyl end-groups (HTPB or HTPI) are irreplaceable in the number of fields where materials with high frost-, waterresistance and insulation properties are requisite [1]. To obtain the materials of high quality, oligodienes with two hydroxyl end-groups (telechelic ones) are most pertinent giving the possibility of creating regular vulcanization network [2]. Recently these oligomers have begun to be used as effective modifiers of resinoplasts - composites based on thermoplasts and elastomers [3-5]. For this purpose it is desirable to have the more quantity of polar groups which supply the interaction between the phases of thermoplast, most often polyethylene, and rubber crumb, as a rule, from secondary sources. The excess groups can be introduced both during synthesis and special modification of double bonds of liquid rubbers.

The most economical method of synthesis HTPB and HTPI $[6,7]$ is diene polymerization in alcoholic solution under hydrogen peroxide (HP) action. Hydrohyl and hydroxyl-containing radical from an alcohol introduce two hydroxyl end-groups into oligomer molecules but under severe conditions of polymerization their number in a molecule may amount to 2.2-2.4 [8] due to chain transfer reactions. Other and more adjustable method of introduction of excess hydroxyl groups may be copolymerization of dienes and hydroxyl-containing monomers, e.g., hydroxyethylmethacrylate [9]. In this work we used an unsaturated allyl alcohol (AA) as a comonomer which is simultaneously a solvent in the polymerization process. Incapability of AA to homopolymerization under these conditions and its high volatility are important advantages of its usage as a source of hydroxyl groups.

\section{Experimental}

\subsection{Materials}

Isoprene from Merck with the content of basic matter $>98 \%$ was distilled before filling dilatometers; the fraction 307.2-307.3 K was chosen. Purified (99.8\%) isopropyl alcohol (IPA) (Merck) was used freshly distilled. HP (production of France) with contents of basic matter $50 \mathrm{wt} \%$ used as received. The good reproducibility shows that such preparation proves to be sufficient.

\subsection{Experiment Preparation and Executing}

Polymerization was conducted in Pyrex ampoules with an inner diameter by $8-10 \mathrm{~mm}$ at $363 \pm 0.1 \mathrm{~K}$ during $10 \mathrm{~h}$. The details of cleaning ampoules and preparation for polymerization were expounded in [10]. The kinetics was determined by dilatometric methods. The calculations were performed proceeding from isoprene contraction $34.5 \mathrm{~cm}^{3} / \mathrm{mol}$ at $363 \mathrm{~K}$ [11]. Taking into account that AA contents in 
cooligomers was low (see below) the difference in contraction values of isoprene and AA was neglected.

After polymerization a reaction mixture was cooled and poured in distilled water. After partial evaporation of isoprene the upper layer of cooligomer was collected and dried in vacuum at $363 \mathrm{~K}$ to achieve a constant weight. The samples were dried up by adding a small quantity of benzene for removing the water traces. The molecular weight was determined by gel chromatography: chromatograph "Waters", columns "Ultrastirogel", eluent tetrahydrofuran, elution rate $1.5 \mathrm{ml} / \mathrm{min}$., $298 \mathrm{~K}$, detector differential refractometer. The system was calibrated on polystyrene standards. The content of hydroxyl groups was found by acetylation with acetic anhydride. Taking into account these data the number averaged molar weight was calculated.

\subsection{Differentiation of Hydroxyl Groups on Reactivity}

To differentiate hydroxyl groups, the methods of kinetic acetylation and FTIR-spectroscopy were used. The first method is described in detail in [12]. The method concerning oligodienes with hydroxyl groups was used in our work [13]. The kinetic acetylation of cooligomer was executed in the acetylation mixture - a solution of acetic anhydride in pyridine $(\sim 0.4 \mathrm{~mol} / \mathrm{l}) .0 \mathrm{ml}$ of initial acetylation mixture was hydrolyzed and titrated by $0.5 \mathrm{~N}$ alcoholic base $\mathrm{KOH}$ for determination of an acetic anhydride concentration. The weighted sample of cooligomer was solved in pyridine, poured together with a required quantity of acetylation mixture, quickly picked out $10 \mathrm{ml}$ of the reaction mixture, poured into water and titrated again. The difference between found and calculated volumes of base doesn't exceed $0.02 \mathrm{ml}$. The molar concentration of acetic anhydride equals to $\sim 0.25 \mathrm{~mol} / \mathrm{l}$, hydroxyl groups $\sim 0.10 \mathrm{~mol} / \mathrm{l}$, so molar ratio was about 2.5 . The samples by $10 \mathrm{ml}$ were picked out from the reaction mixture, poured into $20 \mathrm{ml}$ of water, and after hydrolysis were titrated with the base solution during $0.5 \mathrm{~h}$. The acetylation was conducted at $298 \mathrm{~K}$ in water thermostat to conversion of hydroxyl groups at least $90 \%$. The base volume $\Delta V_{t}$ was used for calculation of conversion:

$$
\alpha=\frac{\Delta V_{t}}{\Delta V_{f}}
$$

where $\Delta V_{f}$ is a calculated base volume of base for conversion by $100 \%$.

The acetylation of hydroxyl groups is submitted by the second order equation:

$$
k t=\frac{1}{(b-a)} \cdot \ln \frac{a(b-x)}{b(a-x)}
$$

where $k$ is a rate constant of acetylation, $a$ and $b-$ concentrations of hydroxyl groups and acetic anhydride, correspondingly, $x$ - a hydroxyl group quantity, having reacted for time $t$.

The dependence $\ln \{[b-x] /[a-x]\}-t$ is a straight line [12], if hydroxyl groups have the same reactivity If two (or more) types of hydroxyl groups with different reactivities are present in a molecule, the line shows a break after that a slope of the line decreases. The contents of more reactive hydroxyl groups $a_{l}$ one finds on a length $A$ on the ordinate axe that is equal:

$$
A=\ln \frac{b-a_{1}}{a-a_{1}}
$$

From a slope of a steeper portion, an acetylation rate constant $k_{2}$ of weaker hydroxyl groups is found.

\subsection{FTIR M easurements}

The reaction of urethane formation between the cooligomer and FIC was conducted [14] at equivalent quantities of hydroxyl and isocyanate groups at ambient temperature $(299 \mathrm{~K})$ directly in the chamber of the spectrophotometer Tensor wiep Fourier transformation. Both components (for this cooligomer the weight ratio cooligomer : FIC was $4.4: 1$ ) were quickly mixed and the mixture was deposited between $\mathrm{NaCl}$ plates and placed on a device tray. The reaction was led to the full disappearance of the isocyanate peak at $2270 \mathrm{~cm}^{-1}$. The initial concentration of isocyanate groups $C_{0}$, eqv/l (that is equal to hydroxyl groups) was calculated from the total volume of the component mixture (considering it additive) by the formula:

$$
C_{0}=[N C O]_{F I C} \cdot \frac{V_{e q v}^{F I C}}{V_{e q v}^{F I C}+V_{e q v}^{o l}}=\frac{1}{V_{e q v}^{F I C}+V_{e q v}^{o l}}
$$

where $[N C O]_{F I C}=\frac{1000 d_{F I C}}{M_{F I C}}=9.1924 e q v / l$ is a concentration of isocyanate groups in FIC; $V_{e q v}^{F I C}-$ a volume of 1 equivalent of isocyanate (in $l$ ); for FIC:

$$
V_{e q v}^{F I C}=\frac{M_{F I C}}{1000 d_{F I C}}=\frac{119.12}{1000 \cdot 1.095}=0.1088
$$

$M_{F I C}$ - FIC molar weight, $d_{F I C}$ - its density; $V_{e q v}^{o l}-\mathrm{a}$ volume of 1 equivalent of oligomer (in $l$ ), that was calculated by formula:

$$
V_{e q v}^{o l}=\frac{M_{e q v}^{o l}}{1000 \cdot d_{o l}}=\frac{1.701}{\% O H \cdot d_{o l}}
$$

Absorption was written in time and the data were treated by the second order equation [14]. The calculations for equal reagent concentrations were performed in the 
form which permits to use band intensities taken straightly from the device:

$$
\frac{C_{0}}{C_{t}}-1=C_{0} k t
$$

where $C_{0}$ and $C_{t}$-initial and current concentrations of isocianate groups, eqv/l; $k-$ a rate constant, $1 \cdot \mathrm{mol}^{-1} \cdot \mathrm{s}^{-1} ; t-$ time, min.

The phone intensity at $2000 \mathrm{~cm}^{-1}$ was subtracted. The rate constant was found as a slope of the dependence $\left(\frac{C_{0}}{C}-1\right)_{-} t$, divided on $60 C_{0}$ (for transformation minutes in seconds).

The conversion was calculated by the formula

$$
\alpha=1-C_{t} / C_{0}
$$

\section{Results and Discussion}

\subsection{Polymerization of Isoprene in AA and the Cooligomer Characterization}

AA and its mixtures with variable amounts of IPA, which is a solvent in an industrial process, were used. The compositions of the mixtures were presented in Table 1.
The mole ratio isoprene : HP was throughout 5.00. The polymerization was parallel conducted in an autoclave with single AA for producing the cooligomer for its characterization.

One can see that polymerization rates don't depend on AA contents in the alcohol mixtures and pure AA doesn't polymerize.

To investigate the hydroxyl groups reactivities, a sample of oligoisoprene has been synthesized in an autoclave (Table 1). Its chromatogram (Fig. 2) is typical for oligoisoprene in this process, but the molecular weight is noticeably lower (Table 2).

A functionality calculated from hydroxyl group contents $\% \mathrm{OH}=3.27$ is equal to $\bar{f}_{n}=3.42$. Considering that bifunctional molecules in homopolymer are formed,

$\bar{f}_{n}=2.0$, allyl alcohol molecules introduce on average into every cooligomer molecule $\sim 1.5$ hydroxyl groups. Apparently, hydroxyl groups contents may be controlled both by ratio allyl alcohol: isopropyl and allyl alcohol : isoprene.

The isoprene polymerization curves in the ampoules are shown in Fig. 1.

Table 1

The compositions of polymerization systems at isoprene polymerization in allyl alcohol and its mixtures with

\begin{tabular}{|c|c|c|c|c|c|c|c|c|c|c|c|}
\hline \multirow{4}{*}{$\begin{array}{c}\text { No. } \\
\text { ampoule }\end{array}$} & \multicolumn{11}{|c|}{ Composition } \\
\hline & \multirow{2}{*}{\multicolumn{2}{|c|}{ Isoprene }} & \multirow{2}{*}{\multicolumn{2}{|c|}{ Allyc alcohol }} & \multirow{2}{*}{\multicolumn{2}{|c|}{ HP }} & \multirow{3}{*}{$\begin{array}{l}\text { IPA } \\
\mathrm{ml}\end{array}$} & \multicolumn{3}{|c|}{ Ratios } & \multirow{3}{*}{$\begin{array}{c}\text { Total, } \\
\mathrm{ml}\end{array}$} \\
\hline & & & & & & & & AA//IPA & {$[\mathrm{AA}] / /[\mathrm{Is}]$} & $\{[\mathrm{Is}]+[\mathrm{AA}]\} /[\mathrm{HP}]$ & \\
\hline & $\mathrm{ml}$ & $\mathrm{mol} / \mathrm{l}$ & $\mathrm{ml}$ & $\mathrm{mol} / \mathrm{l}$ & $\mathrm{ml}$ & $\mathrm{mol} / \mathrm{l}$ & & vol. & mol. & mol. & \\
\hline 1 & 7.5 & 5.00 & 0 & 0 & 0.93 & 1.00 & 6.57 & $0: 1$ & 0 & 5.00 & 15 \\
\hline 2 & 7.5 & 5.00 & 3.28 & 3.22 & 0.93 & 1.00 & 3.29 & $1: 1$ & 0.644 & 8.22 & 15 \\
\hline 3 & 7.5 & 5.00 & 4.93 & 4.83 & 0.93 & 1.00 & 1.64 & $3: 1$ & 0.966 & 9.83 & 15 \\
\hline 4 & 0 & 0 & 6.57 & 6.44 & 0.93 & 1.00 & 0 & $1: 0$ & - & 6.44 & 15 \\
\hline autoclave & 125 & 5.00 & 109.6 & 6.44 & 15.4 & 1.00 & 0 & - & 1.29 & 11.44 & 250 \\
\hline
\end{tabular}
isopropyl alcohol

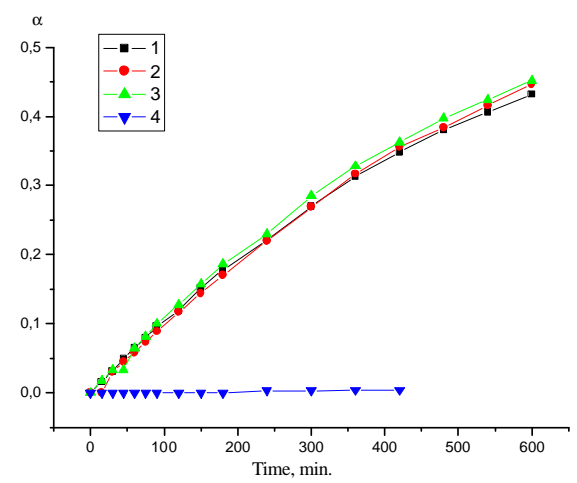

Fig. 1. The kinetic curves of isoprene polymerization in the isopropyl and allyl alcohol mixtures. The content of allyl alcohol in mixture, vol \%: 0 (1); 50 (2); 100 (3) and 100 (4) without isoprene

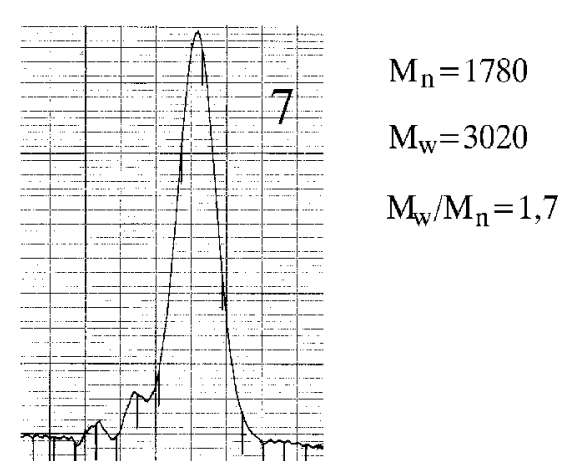

Fig. 2. The chromatogram of the isoprene-allyl alcohol cooligomer 
Molecular characteristics of the isoprene-allyl alcohol cooligomer

\begin{tabular}{|l|c|c|c|c|c|}
\hline \multicolumn{1}{|c|}{ Samples } & $\bar{M}_{w}$ & $\bar{M}_{n}$ & $\bar{M}_{w} / \bar{M}_{n}$ & OH content, wt \% & Functionality, $\bar{f}_{n}$ \\
\hline Cooligomer isoprene-AA (co-Is-AA) & 3020 & 1780 & 1.7 & 3.27 & 3.42 \\
\hline Oligoisoprene (OIs) & 3920 & 2325 & 1.7 & 1.47 & 2.01 \\
\hline
\end{tabular}

\subsection{Cooligomer Kinetic Acetylation}

The kinetic curve of the isoprene-AA cooligomer is presented in Fig. 3. Although the plots show some scattering, the correlation coefficients $\mathrm{R}$ are rather high. Two straight parts are distinctly observed on the curve. The intersection $A$ of the upper part of the curve and its slope $B$ were used for calculation of the contents of the stronger hydroxyl groups and the rate constant of the weaker ones in the acetylation reaction. They were taken from Fig. 3 and shown in Table 3. It is followed from these data, that every sixth HG is weaker than the rest. If we suppose that hydroxyl groups, which are in excess over 2 , are weaker, their contents ought to be $(3.42-2) / 3.42=0.415(41.5 \%)$. It means that such an approach doesn't fit to explain these data. Apparently, the content of the weaker hydroxyl groups is caused by the more complex balance of reactivity in the units of various microstructures, the length of branches, and other chain parameters. We point out that the rate constant of hydroxyl groups in AA monomer equals to
$6.68 \mathrm{l} \cdot \mathrm{mol}^{-1} \cdot \mathrm{s}^{-1}$ that is higher than that in the cooligomer $\left(4.85 \mathrm{l} \cdot \mathrm{mol}^{-1} \cdot \mathrm{s}^{-1}\right)$.

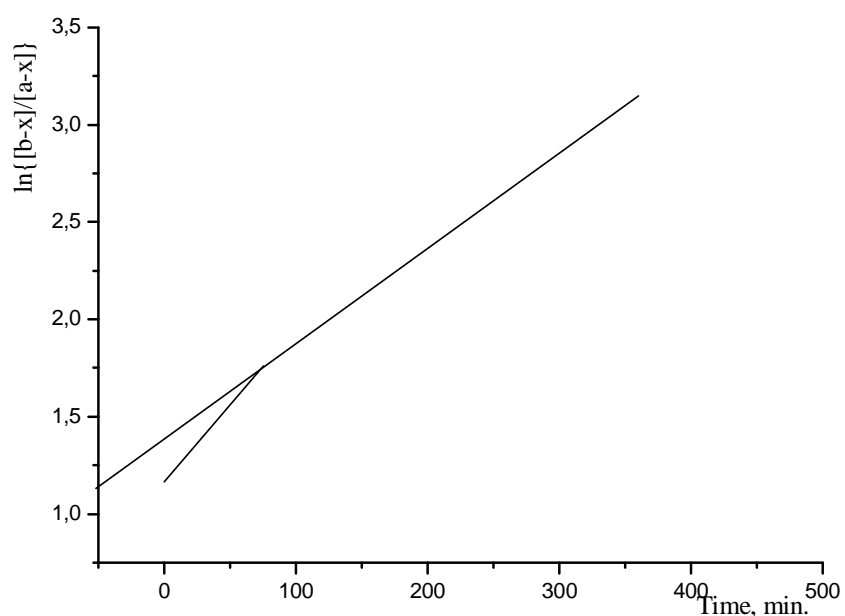

Fig. 3. The curve of kinetic acetylation of isoprene-allyl alcohol cooligomer

Table 3

The data on hydroxyl group reactivities in isoprene-allyl alcohol cooligomer

\begin{tabular}{|c|c|c|c|c|c|}
\hline Time range, min. & $A$ & $B$ & $R$ & $k_{2} \cdot 10^{4}, 1 \mathrm{~mol}^{-1} \mathrm{~s}^{-1}$ & Content of weaker HGs, mol \% \\
\hline $0-30$ & 1.14911 & 0.00762 & 0.9968 & - & 17.1 \\
\hline $30-360$ & 1.20577 & 0.00545 & 0.9994 & 4.85 & - \\
\hline
\end{tabular}

\subsection{Kinetics of Urethane Formation}

The rate constant of the urethane formation reaction shows a very complicated behavior and depends on many factors [15]. So we tried to exclude the majority of the influencing factors such as solvent influence, different reactivity of isocyanate groups in diisocyanates, catalysis by special catalysts. Thus the reaction of this cooligomer with phenyl isocyanate (FIC) at equimolar ratio in bulk at ambient temperature ( $299 \mathrm{~K}$ ) was carried out.

The total kinetic curve is presented in Fig. 4 (the time dependence of isocyanate group conversion) and Fig. 5 (the dependence in the second order coordinates). More information may be obtained from representation of these data in the increased scale (Fig. 6). We can see well formed five straight line parts with the high correlation coefficients. The visible separated sections of the total curve were approximated by the straight line and their intersection points specified the limits of the sections. The rate constants of each of them were calculated (Table 4).

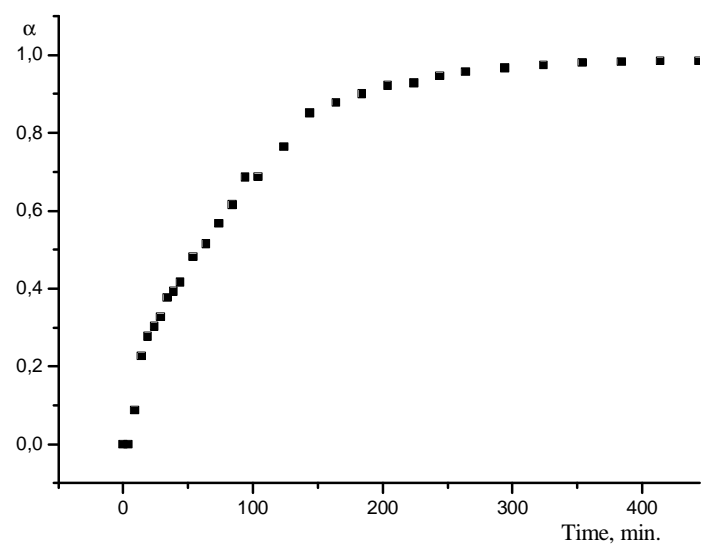

Fig. 4. The curve of hydroxyl group conversion 


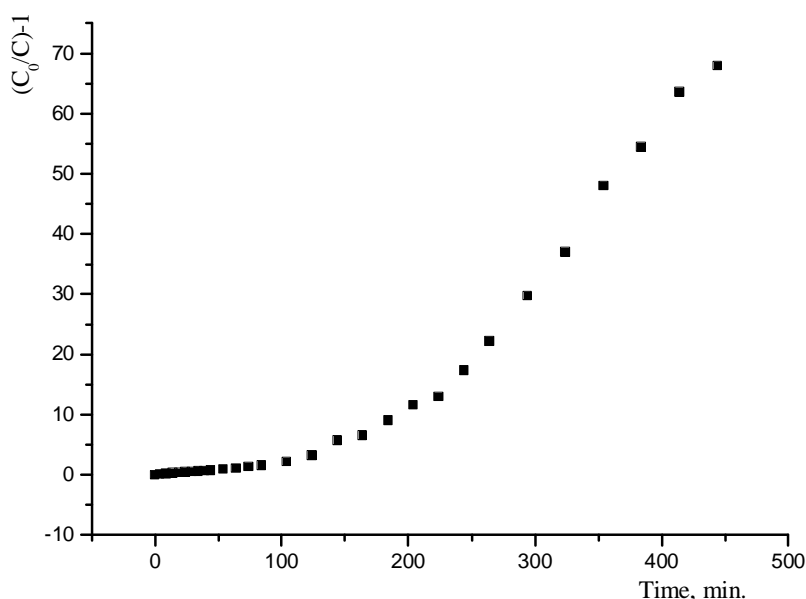

Fig. 5. The total kinetic curve of the urethane formation reaction in the coordinates of the second order

The nature of the straight line parts on the kinetic curve cannot be clearly interpret from these data. Decreasing rate constant on the 2 part (see Table 4) is probably connected with decreasing reactivity of hydroxyl groups, and the following increasing reflects catalysis with forming urethane groups. The two processes are balanced in such a way that slowing down of the reaction takes place in the time interval of 16-66 min. The rise of rate after 66 min may be explained, in the first place by the structural changes of the reaction medium.

The acceleration of the urethane formation reaction in time is well known in the polyurethane chemistry and is explained by the catalysis of forming urethane and other functional groups [15]. The reaction isn't always submitted to the second order equation, so sometimes the third order equation is used [16], which takes into account the influence catalysis both as an initial hydroxy-containing component and the forming urethane. However, in spite of the perfect mathematical description of the kinetic dependences, the true nature of catalysis in the urethane
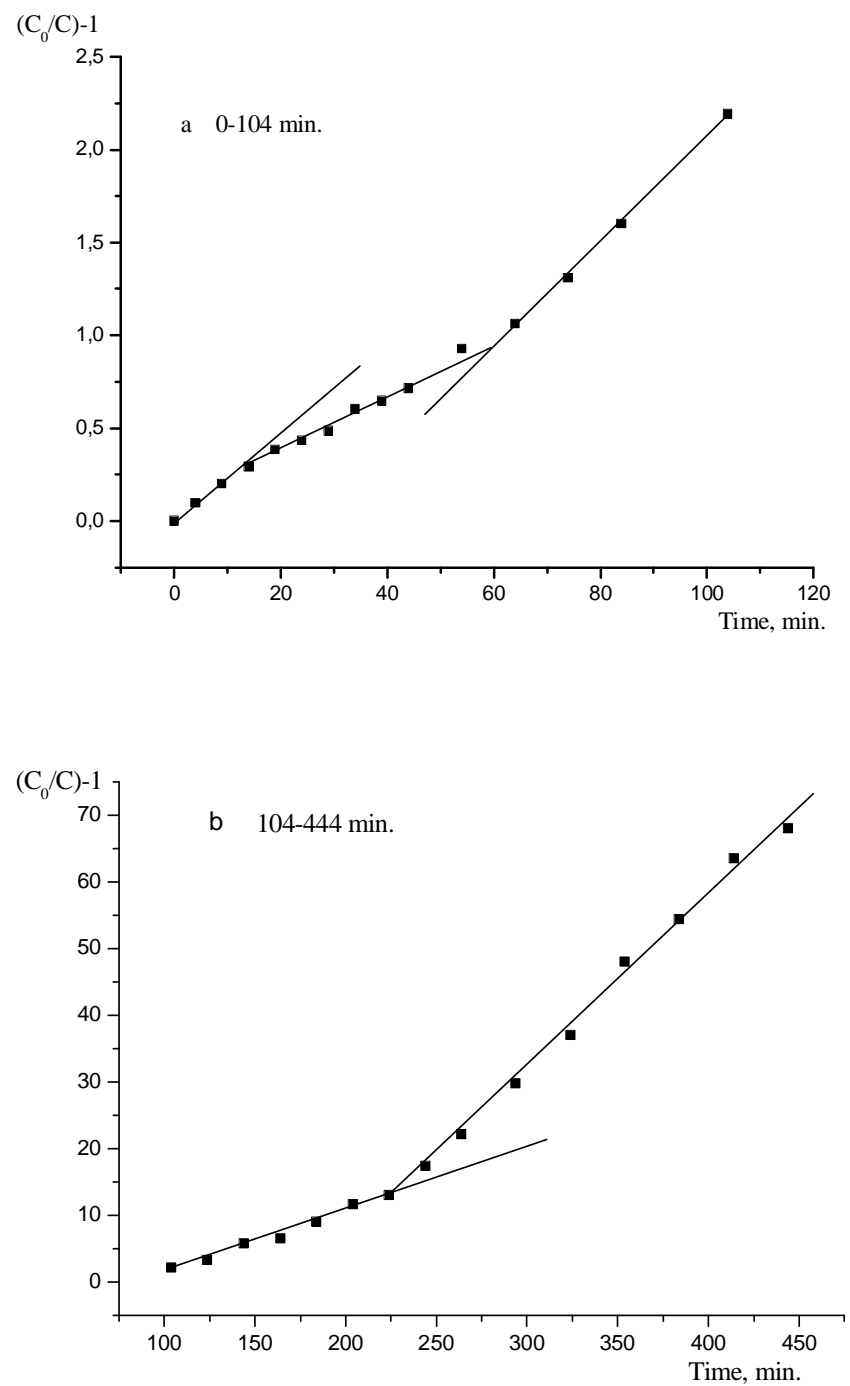

Fig. 6. The initial part of the kinetic curve 0-104 min (a) and the final part 104-444 $\min (\mathrm{b})$

Table 4

The rate constants and contents of hydroxyl groups of various types in cooligoisoprene synthesized in allyl alcohol

\begin{tabular}{|c|c|c|c|c|c|c|}
\hline \multirow{2}{*}{ Section } & \multirow{2}{*}{$\begin{array}{c}\text { Time range, } \\
\text { min. }\end{array}$} & \multirow{2}{*}{$\begin{array}{c}\text { Conversion } \\
\text { range (visible) }\end{array}$} & \multirow{2}{*}{ Slope ratio } & \multirow{2}{*}{$\begin{array}{l}\text { Rate constants, } \\
\qquad k_{2} \cdot 10^{4}\end{array}$} & \multicolumn{2}{|c|}{ Intersection points } \\
\hline & & & & & Time, min. & Conversion \\
\hline 1 & $0-19$ & $0-0.277$ & 0.02006 & $2.323 \pm 0.067$ & 16 & 0.261 \\
\hline 2 & $24-64$ & $\begin{array}{l}0.302- \\
0.515\end{array}$ & 0.01609 & $1.864 \pm 0.075$ & 66 & 0.529 \\
\hline 3 & 64-104 & $0.515-0.687$ & 0.02849 & $3.300 \pm 0.079$ & 117 & 0.755 \\
\hline 4 & $124-224$ & $0.764-0.946$ & 0.09833 & $11.39 \pm 0.065$ & 229 & 0.934 \\
\hline 5 & 224-444 & $0.946-0.985$ & 0.26139 & $30.27 \pm 0.072$ & - & - \\
\hline \multicolumn{4}{|c|}{$\mathrm{V}_{0} \cdot 10^{4}$} & 5.032 & & \\
\hline
\end{tabular}


formation reaction is controversial and constants are imaginary, because they depend on the data treating method. Some theories of catalysis exist in this reaction [15] but the difficulties of the choice of the model systems and the influence of variety of many factors on the reaction rate impede the data simple interpretation. Hydroxyl groups in oligodienes obtained with HP are of diverse nature because of a complex character of initiation, different structure of units, in which hydroxyl groups are located, side transfer reactions into chain and side branches, etc. [17]. The data from [16] reveal that microstructure of end units is not reflected on the reactivity of hydroxyl groups. It suggests that different reactivities of hydroxyl groups are determined not by the position of hydroxyl groups in the end units of a chain or in the chain itself but by their location in associates of various structures. The formation of the associates is caused by segregation of polar hard and non-polar flexible blocks of polyurethane polymers. The segregation of hydrocarbon chains in polyurethanes by a polydiene hydroxy-containing component appears to be stronger than in those with polyether component [18] because of a great difference in polarity of hydrocarbon matrix and polar domains of hard blocks. In the process of phase segregation the more favorable conditions for reaction acceleration are realized as a reaction in non-polar phase proceeds slowly as a result of a low concentration in it of polar hydroxyl groups. The graded course of a reaction is probably explained by discrete structural transformation of polar domains, in which hydroxyl groups were introduced along with FIC molecules. It has been ascertained that association of hydroxyl groups with isocyanate ones in the bulk of liquid rubbers accelerates the urethane formation reaction [19, 20]. The authors [21] announce that the formation of alcohol micelles in nonpolar reactionary mixture owing to increasing a local concentration of hydroxyl groups also speeds up the reaction. It is well known [22] that micelles can stepwise change their forms in dependence of medium and micelle forming agent concentration, in this case in non-polar environment. So this transformation can be a reason of stepwise change in the reactivity of this reaction. The more clear understanding of this picture requires an additional study of the reaction of FIC with hydroxyl-containing oligodienes of various structures.

In the described situation an initial velocity of the urethane formation reaction $V_{0}$ is the most suitable characteristic of reactivity of hydroxyl groups. Of course, the less reactive hydroxyl groups contribute to the reaction velocity but the contribution of urethane catalysis is excluded. The knowledge of an initial velocity for homopolymer is desirable for comparison.

\subsection{Trial Curing Isoprene-AA Cooligomer}

We have conducted some preliminary experiments on curing the cooligomer synthesized in AA solution, without optimization of properties, only for illustration of its specified properties. The comparable samples were obtained according to a typical method using 1,4-butanediol $(1,4-\mathrm{BD})$ as an extender and glycerol as a branching agent. The compositions and properties of polyurethanes are presented in Table 5.

Table 5

\section{Curing the oligomer synthesized in isopropyl alcohol and the cooligomer synthesized in allyl alcohol}

\begin{tabular}{|l|c|c|c|c|c|}
\hline $\begin{array}{c}\text { Alcohol, used for } \\
\text { synthesis, 1 eqv. }\end{array}$ & $\begin{array}{c}\text { Extender, } \\
0.5 \text { eqv. }\end{array}$ & $\begin{array}{c}\text { Branching agent, } \\
0.1 \text { eqv. }\end{array}$ & $\begin{array}{c}\text { Curing agent, } \\
1.65 \text { eqv. }\end{array}$ & $\begin{array}{c}\text { Tensile strength, } \\
\mathrm{MPa}\end{array}$ & $\begin{array}{c}\text { Elongation at } \\
\text { break, } \%\end{array}$ \\
\hline Isopropyl & $1,4-\mathrm{BD}$ & Glycerol & PIC* & 0.17 & 133 \\
\hline Isopropyl & $1,4-\mathrm{BD}$ & Allyl cooligomer & PIC & 0.50 & 128 \\
\hline Allyl & 1,4-BD & - & PIC & 3.67 & 31 \\
\hline
\end{tabular}

Note: PIC - liquid polyisocyanate, $31 \%$ NCO

One can see that the oligomer obtained in the isopropyl alcohol has a low strength and moderate elongation. The change of glycerol as a branching agent considerably increases the strength without loss of elasticity. The cooligomer cured without glycerol has far high strength than other samples but low elongation, that can be explained by low regularity of vulcanized network. Hence, cooligomer may be used as an effective addition at curing of hydrophobic oligomers.

\section{Conclusions}

1. Radical polymerization of isoprene under the action of hydrogen peroxide in allyl alcohol solution leads to formation of isoprene-allyl alcohol copolymer which has an increased (>2) functionality by hydroxyl groups. Concerning an oligomer yield allyl alcohol doesn't differ from isopropyl alcohol, which is used in this process.

2. Hydroxyl groups in the cooligomer differ in reactivity, which was shown by the acetylation method. But the content of less reactive hydroxyl groups does not agree with a calculated one if it is assumed that two hydroxyl end-groups have other reactivity than the excessive ones.

3. FTIR spectroscopy showed a graded course of the reaction of hydroxyl groups with isocyanate ones, calculated according to the aquation of the second order. It may reflect the structure changing of polar domains in 
which the reaction takes place. This cooligomer may cure itself or serve as a hydrophobic branching agent in the polyurethane composition.

\section{References}

[1] Grishchenko V. and Boiko V.: Khim. Prom. Ukrainy, 2004, 4, 11. [2] Oberth A.: AIAA J., 1978, 16, 919.

[3] Boiko V., Ageeva V., Ermol'chuk L. et al.: Polymernyi Zh., 2007, 29, 137.

[4] Raju T., Ding Y., He Y. et al.: Polymer, 2008, 49, 278.

[5] Ermol'chuk L., Boiko V., Grishchenko V. and Lebedev E.:

Voprosy Khim. i Khim. Technol., 2008, 5, 33.

[6] www.sartomer.com

[7] Pennachi V., Vilar V., Cardoso L. and Mignez de Mello L.: Eur. Adhes. and Sealants, Part I, 1988, 2, 20; Part 2, 14.

[8] Vilar W., Menezes S. and Akcelrud L.: Polym. Bull., 1994, 33, 557.

[9] Kulikov V., Basov B., Lysanov V. et al.: Proizvodstvo i Ispolsovanie Elastomerov, 1993, 5, 10.

[10] Boiko V.: Chem. \& Chem. Technol., 2010, in press.

[11] Grishchenko V. and Spirin Yu.: Vysokomol. Soedin. A., 1969, 11, 980.

[12] Siggia S. and Hanna J.: Kolichestvennyi Organicheskiy Analiz po Funkcionalnym Grupam. Khimiya, Moskwa 1983.

[13] Ermol'chuk L., Boiko V., Grishchenko V. et al.: Polymernyi Zh., 2008, 30, 76.

[14] Boiko V., Otapyuk S. and Grishchenko V.: ibid, 71.

[15] Caraculacu A. and Coseri S.: Prog. Polym. Sci., 2001, 26, 799.

[16] El Ghafari M. and Pham Q.: Macromol. Chem., 1983, 184, 1669.

[17] Boiko V. and Dyakova A.: Polymernyi Zh., 2005, 27, 220.
[18] Tereshatov V., Tereshatova E. and Volkova E.: Vysokomol. Soedin. A., 1985, 37, 1881.

[19] Cunliffe A., Davis A., Farey M. and Wright J.: Polymer, 1985, 26, 301 .

[20] El Ghafari M. and Pham Q.: Macromol. Chem., 1983, 184, 1669.

[21] Tarasov D., Tiger R., Entelis S. et al.: Kinetika i Kataliz , 1999, 40, 32.

[22] Korolev G., Ilyin A., Mogilevich M. et al.: Vysokomol. Soedin. A., 2003, 45, 883 .

\section{СИНТЕЗ ТА ХАРАКТЕРИСТИКА ОЛІГОІЗОПРЕНУ, ОДЕРЖАНОГО В РОЗЧИНІ АЛІЛОВОГО СПИРТУ В ПРИСУТНОСТІ ПЕРОКСИДУ ВОДНЮ}

Анотація. Синтезовано кополімер ізопрену та алілового спирту під дією пероксиду водню. Використання змішаного розчинника ізопропіловий-аліловий спирт показало, щчо вихід олігомеру не залежить від складу розчинника. Полімеризачія одного алілового спирту не відбувається. Визначення молярних мас $i$ вмісту гідроксильних груп в олігомерах, одержаних в обох спиртах, показала, щзо олігомер, одержаний в розчині алілового спирту, містить 3,5 гідроксильних групи проти 2 - в розчині одного ізопропілового спирту.

Ключові слова: кополімеризація, ізопрен, аліловий спирт, пероксид водню, гідроксильні групи, функиіональність. 